\title{
The influence of coloured light in the aircraft cabin on passenger thermal comfort
}

\author{
J Winzen PhD, F Albers PhD and C Marggraf-Micheel PhD \\ German Aerospace Centre, Aviation and Space Psychology, Hamburg, Germany
}

Received 29 January 2013; Revised 27 February 2013; Accepted 1 March 2013

Coloured light is one aspect of modern aircraft cabin design. It could be used intentionally to influence thermal sensations: Coloured light may convey the impression that the environmental temperature is warmer or cooler than it actually is while still providing thermal comfort. A study was conducted in a light laboratory to test these assumptions. Subjects were exposed to different lighting situations, which were evaluated in terms of light and comfort. It was found that room temperature was perceived as being different depending on the colour of the lighting: In yellow light, room temperature was felt to be warmer than in blue light. Conversely, air quality was perceived as being higher and subjects felt more alert in blue light. All the coloured lighting situations tested were comfortable.

\section{Introduction}

During a flight in a passenger aircraft, various external factors determine the way the passengers experience comfort. Specific environmental factors in the aircraft cabin include physical conditions such as temperature, noise, air quality and light to name a few. ${ }^{1}$ Standards are defined for these factors, which are primarily meant to ensure that the conditions during a flight are not detrimental to the passengers' health (e.g. EN 4618:2009 ${ }^{2}$ or ASHRAE $161-2007^{3}$ ). In order to provide comfort as well, environmental parameters also have to be defined according to the passengers' needs, since their subjective wellbeing is ultimately critical for the degree of comfort in the aircraft cabin. ${ }^{4}$

\subsection{Thermal comfort}

The thermal conditions in an aircraft cabin need to be adjusted in order to obtain certain levels of temperature, air-flow, humidity and

Address for correspondence: Julia Winzen, German Aerospace Center, Sportallee 54a, 22335 Hamburg, Germany.

E-mail: Julia.Winzen@dlr.de air quality that are conducive to a high degree of passenger well-being, as well as avoiding discomfort. ${ }^{5}$ Using the aircraft's environmental control system (ECS), energy is expended to make the passengers on the flight feel comfortable, with temperatures between $22^{\circ} \mathrm{C}$ and $27^{\circ} \mathrm{C}$, an air velocity of less than $0.3 \mathrm{~m} / \mathrm{s}$ at all seats and preferably an average relative humidity of $30 \%{ }^{2}$

A thermal-comfort model can be used as the basis for the investigation of the experienced well-being (subjective well-being) to determine passenger comfort in an aircraft cabin. The 'model for the measurement of thermal comfort' (Figure 1) was designed to illustrate the combination of objective thermal conditions on the one hand, and subjective perceptions and evaluations on the other hand. Both have to be accounted for in order to provide a thorough analysis of thermal comfort. ${ }^{4}$ A given environmental scenario, defined by corresponding parameters (e.g. temperature, air velocity or relative humidity) leads to specific environmental conditions, which can be operationalised by physical parameters. The objective parameters affect the passengers, who individually process these 


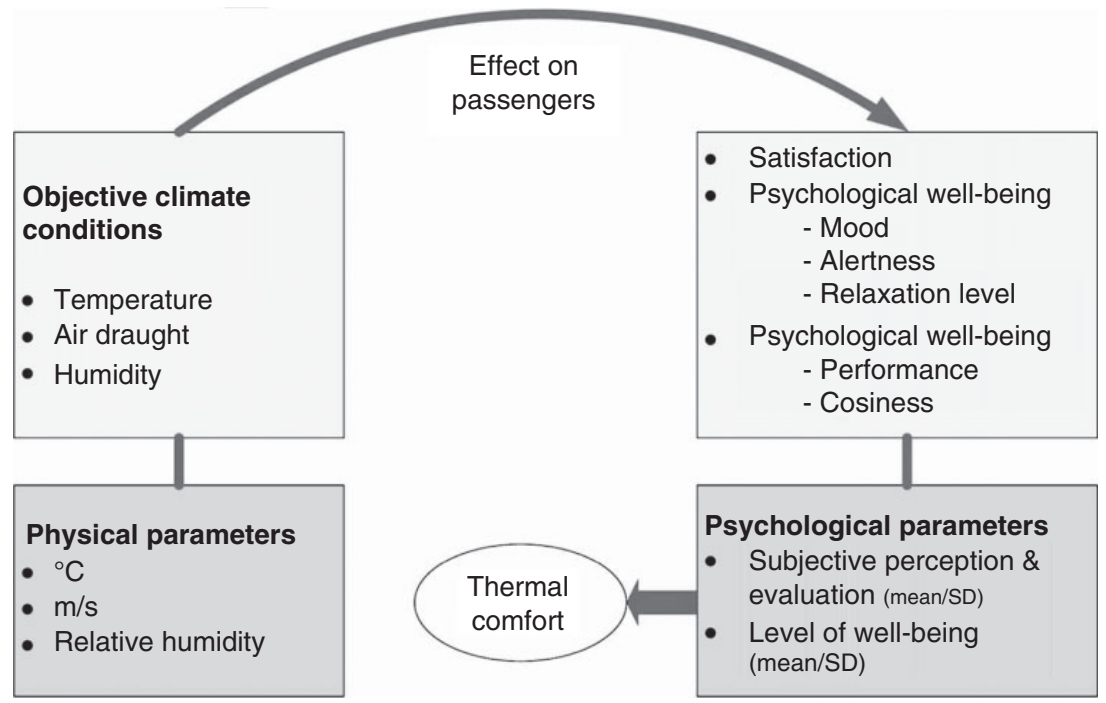

Figure 1 The thermal comfort measurement model

conditions in different ways. The effects on the passengers can be characterised and measured by psychological parameters. The satisfaction with the environmental situation has to be considered as well as the subjective well-being in terms of psychological and physiological aspects. By integrating these criteria, the passengers' level of thermal comfort can be determined.

Studies about the impact of environmental parameters on thermal perception suggest including further factors in thermal comfort models. ${ }^{6,7}$ The colour of the light is an interesting factor to be taken into account in addition to the climatic conditions as it is generally assumed that colour has a certain perceived thermal virtue. ${ }^{8,9}$ With regard to energy conservation in aircraft usage, coloured light seems to be a promising technology to utilise. Today's environmental control systems work with bleed air. A considerable amount of energy is spent when cooling down bleed air to provide breathing air for the cabin. If coloured light can affect thermal sensation, it can be used to create the impression of cooler air in the aircraft cabin and thereby reduce the required power of the ECS. 'Heating up' the aircraft cabin using coloured light may also be interesting for new ECS concepts which include no-bleed electrical system architectures.

\subsection{Coloured light}

Light influences people psychologically and physiologically and its effects have been investigated in various situations, for example its medical and/or therapeutic effects, its effects on performance at work and job satisfaction, on learning efficacy, on purchasing behaviour and also on the perception of comfort at home or while travelling have all been described. ${ }^{10-13}$ In addition to the targeted usage of white light in various hues, coloured lighting has been used to change a room's perceived comfort. Van Hagen et al. ${ }^{13}$ identified the colour of the light as having an influence on a person's condition while waiting on a railway station in a virtual reality experiment.

Generally, the special effect of light and colour in combination appears to have rarely been investigated and documented studies 
raise some methodological issues. Investigations differ partly in their experimental design, for example with the light sources used, the specification of the light situation and the control of the relevant lighting parameters such as glare or brightness. The colours are vaguely or unsystematically defined. Furthermore, there appears to be a lack of reliable and valid measurements of the emotional reactions to light. ${ }^{14-16}$ There have been only a few findings from which results can be generalised.

Colours have previously been characterised according to their psychological effects on factors such as mood, activity-level and performance. ${ }^{17}$ These descriptions are primarily related to the effects of non-luminous colours. Some of the results of these studies concerning coloured surfaces ${ }^{16}$ have been generalised to describe the effect of coloured light. ${ }^{18}$ However, it seems doubtful that these generalisations are appropriate. The effects of coloured light appear to differ, particularly from the arousal effect of non-luminous colours. Such is the case for blue light especially with a wavelength of approximately $460 \mathrm{~nm}$ - which demonstrates an arousing effect, since melatonin suppression sets in during exposure to this colour of light. ${ }^{19,20} \mathrm{In}$ contrast, a soothing effect is reported for a non-luminous blue colour. ${ }^{16}$ Further findings concerning coloured light and its influence on circadian biology and melatonin suppression have been reported in medical research. Several studies point out that coloured light is an important modulator of alertness, performance and cognition. Main effects were shown for short wavelength light (blue) as compared to longer wavelength light (green). ${ }^{21-23}$

\subsection{Thermal effect of coloured light}

The specific goal of this study is the analysis of the effects of coloured light to determine its psychological influence on the perception of temperature. In this context, the categorisations of 'warm' and 'cold' colours are employed. ${ }^{8}$ Red, yellow and orange are considered 'warm' colours; blue, green and violet belong to the group of 'cold' colours. Investigations in this field are based on the 'hue-heat hypothesis', which was summarised by Bennett and Rey. ${ }^{24}$ This hypothesis claims that 'cold' hues lead to the perception of cooler temperatures, while 'warm' hues lead to the perception of higher temperatures. Several studies have used coloured surfaces to test the hue-heat hypothesis. Differing results have been reported supporting and refuting the hypothesis. ${ }^{6,7}$

The relevant results of the studies on the effect of coloured light on the perception of temperature also lead to conflicting conclusions. Several investigations were unable to demonstrate that coloured light had any effect on the perception of temperature. ${ }^{6,25}$ As opposed to this, Fanger, Breum and Jerking demonstrated that at an objectively equal room temperature, red light led to the perception of higher temperatures, whereas blue light created the perception of a colder temperature. ${ }^{26}$ They reported a $0.4^{\circ} \mathrm{C}$ difference in temperature perception between a strongly saturated blue light and red light.

The environmental control system of an aircraft cabin should maintain the comfort level in an energy-efficient way. Coloured lighting could be used in this context in combination with the ECS to affect the thermal perception of the passengers. More specifically, coloured light could be used in such a way, that the well-being of the passengers is enhanced by changing their perceived thermal comfort depending upon their needs, by making it seem warmer or cooler.

Based on a thorough literature review, a first study was conducted in a light-laboratory, where different lighting colours were pre-tested with regard to their effects on the subjects' thermal perception and comfort. ${ }^{27}$ The setting of the study including measurement design, instruments and participants 
$(N=59$; mean age $=21.37$ years; $S D=2.39)$ was comparable to the present study. Basically, a thermal effect was confirmed for blue and yellow: All three hues of blue were qualified as appearing cooler than yellow. Furthermore, the room temperature was generally perceived as being cooler in all three blue light conditions.

\subsection{Hypotheses}

The following hypotheses were generated within the context of the aforementioned thermal-comfort model. Coloured light defined by its physical parameters (e.g. brightness, colour temperature) is considered as a moderating variable which influences the effect the objective climate conditions have on the passengers.

Hypothesis 1: Coloured light affects the perception of room temperature in an aircraftlike environment. More specifically, yellow light creates a perception of warmer temperatures and blue light a perception of cooler temperatures.

Hypothesis 2: Coloured light has an influence on the psychological and physiological wellbeing of the subjects in an aircraft-like environment. Yellow and blue have positive effects on the perceived comfort.

\section{Method}

\subsection{Participants and design}

This experiment involved the participation of 59 people ( $n=41$ men and $n=18$ women) with normal colour vision. Their mean age was $M=21.78$ years $(S D=2.65)$. All participants were applicants for a position as a student pilot with a major German airline. They participated voluntarily in this study after their assessment at the German Aerospace Centre (DLR) in Hamburg. All subjects were high-school graduates qualified to study at a university (German 'Abitur').
They were paid $€ 15$ each for their participation.

Data were collected using a one-factorwithin-subjects design with repeated measures. The independent variable was the lighting situation in a light-laboratory. Various dependent variables regarding the perceptions of the lighting situation, personal comfort and thermal sensation were utilised.

\subsection{Instruments}

The experiment took place in a lightlaboratory on the premises of the DLR in Hamburg. This laboratory is designed as a mock-up cabin of a single-aisle aircraft. It has 10 'passenger seats' (simple chairs) in three rows facing a life-size photograph of an aircraft cabin with passengers at the front end of the room. The ceiling design contributed to the illusion of an aircraft cabin.

The laboratory was equipped with a lighting system with high power LEDs installed in two rows on the ceiling, also resembling the installation in an aircraft. The lighting system consisted of high power RGB multichip LEDs $(3 \times 1 \mathrm{~W} / 350 \mathrm{~mA})$ with 20 LEDs $/ \mathrm{m}$ with approximately $60 \mathrm{~W} / \mathrm{m}$. Figure 2 shows the light-laboratory.

Four different coloured lighting situations and one neutral lighting situation were used.

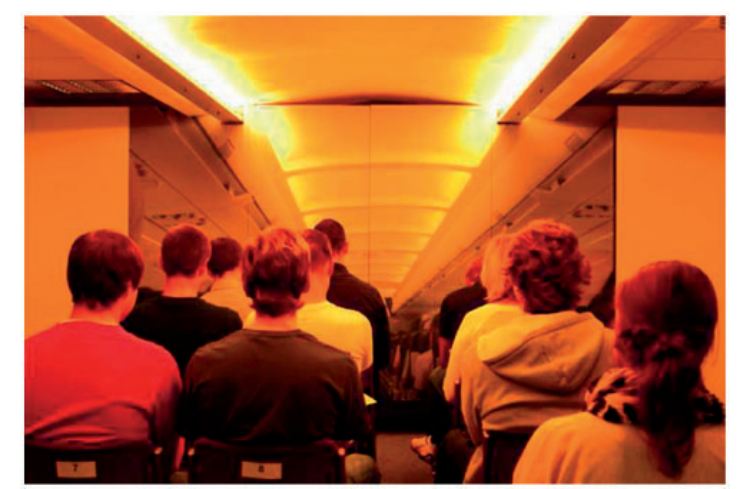

Figure 2 Light-laboratory $\mathbb{C}$ Jan Brandes/Luftfahrtcluster Metropolregion Hamburg 
The four coloured scenarios were derived from our first study in the light-laboratory. ${ }^{27}$ Two blue and two yellow hues were chosen which had proven to be most useful and comfortable in the preceding experiment: The two hues of blue (names: B1, B2) can be described as light blue with different proportions of red and green. They were chosen with the intention of inducing a cooler sensation of room temperature. The two hues of yellow (names: Y1, Y2) can be described as orangeyellow with different proportions of green. They were meant to induce a warmer temperature sensation. The neutral lighting situation (name: $\mathrm{N}$ ) was artificial daylight. Table 1 shows the RGB values that were selected in the control software to establish the respective lighting situations. Additionally, the measured centroid wavelengths, chromaticity coordinates and illuminances of the four coloured lighting situations as well as the neutral lighting situation are given. Centroid wavelengths and chromaticity coordinates as well as illuminances were measured with a spectroradiometer (specbos 1211, spectral range $350-1000 \mathrm{~nm}$ ) and were averaged over all experimental sessions.

Several psychological variables were measured using questionnaires. All questionnaires were administered on pocket PCs (HP iPAQ214, 4" TFT touch screen display, input by stylus pen).

The instrument for the assessment of thermal comfort has previously been successfully evaluated in several studies using aircraft cabin mock-ups. ${ }^{28}$ The first part of the questionnaire consisted of demographic data. Part two of the questionnaire comprised different scales regarding the dependent variables. In order to measure the effects of the lighting and its colour, the perception and evaluation of brightness and the colours' temperature appearance were considered. In a first step the perception of a parameters' intensity was rated (e.g. How intense is the colour's brightness?). In a second step, the amount of comfort this intensity induces was evaluated (e.g. How comfortable is the colour's brightness?). Perception was rated on a seven point rating scale (brightness: $1=$ very dark to $7=$ very light; temperature appearance: $1=$ very cold to $7=$ very warm); evaluation was assessed with a five point rating scale, ranging from $1=$ very uncomfortable to $5=$ very comfortable. Regarding climate effects, four climate parameters were assessed: The perception and evaluation of room temperature, air quality, air draught and humidity. Again, perception was measured on a seven point rating scale (temperature: $1=$ very cold to $7=$ hot; air draught: $1=$ not at all to $7=$ strong; humidity: $1=$ very dry to $7=$ very humid; air quality: $1=$ very stifling to $7=$ very fresh) and evaluation on a five point rating scale ranging from $1=$ very uncomfortable to $5=$ very comfortable. Additionally, preferences concerning the current temperature were assessed.

Table 1 Lighting situations with their respective selected RGB values and measured average centroid wavelength, chromaticity coordinates and illuminance

\begin{tabular}{|c|c|c|c|c|c|c|c|}
\hline \multirow[b]{2}{*}{ Lighting situation } & \multirow[b]{2}{*}{$\mathrm{R}$} & \multirow[b]{2}{*}{ G } & \multirow[b]{2}{*}{ B } & \multirow{2}{*}{$\begin{array}{l}\text { Centroid } \\
\text { wavelength }(\mathrm{nm})\end{array}$} & \multicolumn{2}{|c|}{ Chromaticity coordinates } & \multirow{2}{*}{$\begin{array}{l}\text { Illuminance } \\
\text { (lux) }\end{array}$} \\
\hline & & & & & $x$ & $\mathrm{y}$ & \\
\hline Y1 & 255 & 165 & 0 & 603.22 & 0.552 & 0.411 & 134.93 \\
\hline Y2 & 255 & 150 & 0 & 607.10 & 0.572 & 0.396 & 123.90 \\
\hline B1 & 130 & 235 & 255 & 496.77 & 0.183 & 0.184 & 175.30 \\
\hline B2 & 160 & 255 & 255 & 504.58 & 0.198 & 0.201 & 200.40 \\
\hline $\mathrm{N}$ & 255 & 255 & 251 & 527.48 & 0.249 & 0.220 & 222.52 \\
\hline
\end{tabular}

Note: RGB scale 0-255. Y: Yellow; B: Blue; N: Neutral. 
For the measurement of subjective wellbeing (Table 2), parts were taken from two different published German questionnaires: Three scales on psychological well-being were taken from the "Multidimensional questionnaire of subjective well-being, ${ }^{29}$ namely alertness, mood and relaxation level. Two further scales on physiological well-being (performance and cosiness) were derived from the 'Questionnaire for the assessment of current physiological well-being. ${ }^{30}$ Each scale was comprised of eight items which were rated on a five stage Likert scale.

\subsection{Procedure}

The experiment was conducted in 6 sessions with 10 participants each (except 1 session with 9 participants). Temperature, air velocity and humidity were kept constant and not manipulated. Values were measured twice in each session at the beginning and the end. The mean temperature in the light-laboratory was $22.2^{\circ} \mathrm{C}(S D=1.2)$, relative air humidity was $62 \%(S D=4.0)$. Since there was no air

Table 2 Scales assessing subjective well-being

\begin{tabular}{lll}
\hline Well-being & Scales & $\varnothing$ Reliability, $\alpha$ \\
\hline Psychological & Alertness & $0.84(0.80-0.89)$ \\
well-being & Mood & $0.74(0.72-0.75)$ \\
& Relaxation level & $0.72(0.68-0.74)$ \\
Physiological & Efficiency & $0.82(0.79-0.85)$ \\
well-being & Cosiness & $0.73(0.70-0.79)$ \\
\hline
\end{tabular}

Note: Reliabilities (average and range) obtained in current sample $(N=59)$. conditioning in the laboratory, air velocity was non-existent.

At the beginning of each session, participants were given standardised instructions for the experiment on how to fill in the questionnaires on the pocket PCs. Following the instructions, participants completed the first part of the questionnaire. After that, they were exposed to the four lighting situations in succession. Both hues of the two colours, yellow and blue, were alternated in succession during one session. The order of exposure was varied in each of the six experimental sessions (Figure 3). This procedure, balanced exposure to lighting scenarios and (quasi-) random assignment of participants to the experimental sessions, controls for confounding influences like differential light exposure before the study or order related effects.

Each exposure to a coloured lighting situation lasted 9 minutes. After each of these exposures, participants were asked to answer all questions of part two of the questionnaire while the lighting situation remained unchanged. Before the next exposure to a coloured lighting situation began, participants were exposed to the neutral lighting situation for 1 minute to neutralise their colour impressions. The whole procedure lasted about 60 minutes. During exposure, participants were entertained with podcasts about scientific space research. They were instructed to look towards the front, to remain quiet and to concentrate on the auditory material.

\begin{tabular}{|c|c|c|c|c|c|c|c|c|c|}
\hline $\begin{array}{c}\text { Experimental } \\
\text { session }\end{array}$ & & Scenario 1 & & Scenario 2 & & Scenario 3 & & Scenario 4 & \\
\hline 1 & \multirow{6}{*}{ 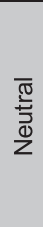 } & Y1 & \multirow{6}{*}{ 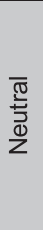 } & B1 & \multirow{6}{*}{ 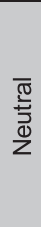 } & Y2 & \multirow{6}{*}{ 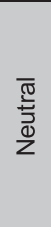 } & B2 & \multirow{6}{*}{$\begin{array}{l}\overline{\widetilde{\pi}} \\
\overline{3} \\
\frac{0}{2}\end{array}$} \\
\hline 2 & & Y2 & & B2 & & Y1 & & B1 & \\
\hline 3 & & Y1 & & B2 & & Y2 & & B1 & \\
\hline 4 & & B1 & & $\mathrm{Y} 1$ & & B2 & & Y2 & \\
\hline 5 & & B2 & & Y2 & & B1 & & Y1 & \\
\hline 6 & & B1 & & Y2 & & B2 & & $\mathrm{Y} 1$ & \\
\hline
\end{tabular}

Figure 3 An overview of the order of lighting scenarios in all six experimental sessions $(Y=y e l l o w, B=b l u e)$ 
Table 3 Descriptive statistics and analyses of variance with repeated measures for the effects of lighting colour on lighting perception and evaluation

\begin{tabular}{|c|c|c|c|c|c|c|c|c|c|}
\hline & & \multicolumn{2}{|l|}{ Yellow } & \multicolumn{2}{|l|}{ Blue } & \multirow[b]{2}{*}{$d f$} & \multirow[b]{2}{*}{$F$} & \multirow[b]{2}{*}{$\eta^{2}$} & \multirow[b]{2}{*}{$p$} \\
\hline & & Y1 & Y2 & B1 & B2 & & & & \\
\hline \multicolumn{10}{|l|}{ Brightness } \\
\hline Perception & $M(S D)$ & $3.90(1.19)$ & $3.93(1.33)$ & $4.92(1.21)$ & $5.15(1.04)$ & 2.34 & 23.88 & 0.29 & 0.00 \\
\hline Evaluation & $M(S D)$ & $3.15(0.99)$ & 3.22 & $3.05(1.08)$ & $3.08(1.08)$ & 2.36 & 0.32 & 0.01 & 0.76 \\
\hline \multicolumn{10}{|l|}{ Temperature appearance } \\
\hline Perception & $M(S D)$ & $5.36(1.04)$ & $5.59(0.85)$ & $2.51(0.96)$ & $2.63(0.94)$ & 2.46 & 223.06 & 0.79 & 0.00 \\
\hline Evaluation & $M(S D)$ & $3.29(0.94)$ & $3.49(0.99)$ & $2.76(0.99)$ & $2.95(1.02)$ & 2.01 & 7.01 & 0.11 & 0.00 \\
\hline General evaluation of the light & $M(S D)$ & $3.07(1.01)$ & $3.20(1.04)$ & $2.92(1.08)$ & $2.98(0.95)$ & 2.15 & 0.96 & 0.02 & 0.39 \\
\hline
\end{tabular}

Note: $N=59$. Perception scales: brightness: $1=$ very dark to $7=$ very light; temperature appearance: $1=$ very cold to $7=$ very warm. Evaluation scales: $1=$ very uncomfortable to $5=$ very comfortable.

Results adjusted according to Greenhouse-Geisser.

\section{Results}

The effects of the lighting colours were tested using analyses of variance with repeated measures. Complete data sets from all 59 participants were available for the analyses.

\subsection{Effects on the perception and evaluation of lighting}

Blue and yellow lights had different effects on the subjects (Table 3). While both blue hues were perceived as being rather light and cool, the yellow shades were rated as significantly darker and warmer. The effect sizes indicated large effects for brightness and the colours' temperature appearance perception ratings. The warmer colour of both hues of yellow was evaluated as being significantly more agreeable than the cooler colour of both hues of blue. The associated general evaluations of the light did not differ from each other significantly - all hues are rated as fairly comfortable.

\subsection{Effects on the perception and evaluation of climate parameters}

In addition to the perception and evaluation of the four lighting colours themselves, we were especially interested in their effects on the perception and evaluation of climate parameters. Results for the comparisons of means are displayed in Table 4 . A room with yellow lighting was perceived as having a significantly higher room temperature than a room with blue lighting. This was true for both hues of yellow; the corresponding effect size was large. Unfortunately, significant differences regarding the perception of the colours' brightness were identified. Therefore it may not be established if this effect was due to the colour itself. As a consequence, the analysis of variance was performed again, controlling for the factor 'brightness'. Controlling for brightness, the effect size was reduced slightly but nonetheless remained significant $\left(F_{(3,231)}=5.41 ; \eta^{2}=0.07 ; p<0.01\right)$. The comfort evaluations of the room temperature did not differ significantly. All temperatures were perceived as being agreeable.

Regarding temperature preferences, different patterns were found for both lighting colours. In blue lighting, $38 \%$ of the participants favoured a higher room temperature while $16 \%$ preferred a lower temperature; $46 \%$ were satisfied with the temperature. In yellow lighting, only $28 \%$ wanted it to be warmer and $19 \%$ favoured a cooler temperature; $53 \%$ of the participants were satisfied with the temperature.

The air quality was perceived as being poorer and described as being more stifling by 
Table 4 Descriptive statistics and analyses of variance with repeated measures for effects of the lighting colour on climate parameters

\begin{tabular}{|c|c|c|c|c|c|c|c|c|c|}
\hline & & \multicolumn{2}{|l|}{ Yellow } & \multicolumn{2}{|l|}{ Blue } & \multirow[b]{2}{*}{$d f$} & \multirow[b]{2}{*}{$F$} & \multirow[b]{2}{*}{$\eta^{2}$} & \multirow[b]{2}{*}{$p$} \\
\hline & & Y1 & Y2 & B1 & B2 & & & & \\
\hline \multicolumn{10}{|l|}{ Room temperature } \\
\hline Perception & $M(S D)$ & $4.31(0.81)$ & $4.20(0.92)$ & $3.59(1.06)$ & $3.66(1.10)$ & 2.61 & 13.02 & 0.18 & 0.00 \\
\hline Evaluation & $M(S D)$ & $3.42(0.92)$ & $3.31(0.93)$ & $3.17(1.01)$ & $3.24(1.08)$ & 3.00 & 0.98 & 0.02 & 0.40 \\
\hline \multicolumn{10}{|l|}{ Air quality } \\
\hline Perception & $M(S D)$ & $3.41(1.25)$ & $3.29(1.07)$ & $3.88(1.46)$ & $3.73(1.38)$ & 3.00 & 5.61 & 0.09 & 0.00 \\
\hline Evaluation & $M(S D)$ & $2.80(1.09)$ & $2.75(0.97)$ & $2.98(1.02)$ & $2.90(1.12)$ & 2.72 & 1.00 & 0.02 & 0.39 \\
\hline \multicolumn{10}{|l|}{ Air draught } \\
\hline Perception & $M(S D)$ & $1.59(0.74)$ & $1.54(0.65)$ & $1.73(0.88)$ & $1.59(0.67)$ & 2.69 & 1.39 & 0.02 & 0.25 \\
\hline Evaluation & $M(S D)$ & $3.49(1.20)$ & $3.44(1.14)$ & $3.27(1.21)$ & $3.37(1.06)$ & 3.00 & 0.72 & 0.01 & 0.54 \\
\hline \multicolumn{10}{|l|}{ Humidity } \\
\hline Perception & $M(S D)$ & $3.66(1.17)$ & $3.80(1.18)$ & $3.90(1.19)$ & $3.81(1.19)$ & 3.00 & 0.94 & 0.02 & 0.42 \\
\hline Evaluation & $M(S D)$ & $3.15(1.07)$ & $3.10(0.92)$ & $3.15(0.94)$ & $3.24(0.91)$ & 3.00 & 0.31 & 0.01 & 0.82 \\
\hline $\begin{array}{l}\text { General evaluation } \\
\text { of the climate }\end{array}$ & $M(S D)$ & $3.00(0.84)$ & $3.10(0.82)$ & $3.08(0.89)$ & $2.95(0.83)$ & 3.00 & 0.65 & 0.01 & 0.58 \\
\hline
\end{tabular}

Note: $N=59$. Perception scales: room temperature: $1=$ very cold to $7=$ hot; air quality: $1=$ very stifling to $7=$ very fresh; air draught: $1=$ no air draught to $7=$ strong air draught; humidity: $1=$ very dry to $7=$ very humid. Evaluation scales: $1=$ very uncomfortable to $5=$ very comfortable. Results adjusted according to Greenhouse-Geisser.

Table 5 Descriptive statistics and analyses of variance with repeated measures for effects of the lighting colour on psychological and physiological well-being

\begin{tabular}{|c|c|c|c|c|c|c|c|c|c|}
\hline & & \multicolumn{2}{|l|}{ Yellow } & \multicolumn{2}{|l|}{ Blue } & \multirow[b]{2}{*}{$d f$} & \multirow[b]{2}{*}{$F$} & \multirow[b]{2}{*}{$\eta^{2}$} & \multirow[b]{2}{*}{$p$} \\
\hline & & Y1 & Y2 & B1 & B2 & & & & \\
\hline \multicolumn{10}{|c|}{ Psychological well-being } \\
\hline Alertness & $M(S D)$ & $2.52(0.74)$ & $2.75(0.98)$ & $3.12(1.01)$ & $3.22(0.95)$ & 2.47 & 9.76 & 0.14 & 0.00 \\
\hline Mood & $M(S D)$ & $3.55(0.80)$ & $3.51(0.91)$ & $3.43(0.89)$ & $3.36(0.88)$ & 2.20 & 1.00 & 0.02 & 0.38 \\
\hline Relaxation level & $M(S D)$ & $3.86(0.89)$ & $3.91(0.92)$ & $3.75(0.90)$ & $3.75(0.90)$ & 2.61 & 0.94 & 0.02 & 0.41 \\
\hline \multicolumn{10}{|c|}{ Physiological well-being } \\
\hline Performance & $M(S D)$ & $2.69(0.89)$ & $2.67(0.89)$ & $3.12(0.88)$ & $3.14(0.88)$ & 2.53 & 9.59 & 0.14 & 0.00 \\
\hline Cosiness & $M(S D)$ & $2.92(0.87)$ & $2.93(0.86)$ & $2.91(0.89)$ & $2.82(0.85)$ & 2.18 & 0.31 & 0.01 & 0.75 \\
\hline
\end{tabular}

Note: $N=59$. Scales: $1=$ not at all to $5=$ completely. Results adjusted according to Greenhouse-Geisser.

the participants during the yellow lighting scenarios. Nonetheless, it was evaluated as more or less comfortable for all four hues. For the climate parameters 'air draught' and 'humidity', no significant differences in the perception or evaluation were observed. Also, the general evaluation of the climate did not differ depending upon the lighting colour; it was rated as being fairly comfortable in all lighting situations.

\subsection{Effects on the psychological and physio- logical well-being}

The participants' well-being differed depending on the colour condition (Table 5). Concerning their psychological well-being, subjects felt significantly more alert in both blue hues, while in yellow light, they felt rather sleepy. However, their alertness in blue light did not exceed a neutral level. Mood and relaxation levels did not vary significantly. 
With regard to their physiological well-being, a large effect was observed for the subjects' performance: They describe themselves as being better able to concentrate and feeling more ready to do something in blue lighting. For the dimension 'cosiness', there was no systematic pattern in the subjects' ratings; all hues induced the same moderate impressions of comfort.

Again, the brightness perception, which differed between blue and yellow, had to be excluded as an explanatory variable. Analyses of covariance including the factor 'brightness' confirmed that brightness had no significant effects regarding the observed differences in combination with either alertness $\left(F_{(1,231)}=\right.$ 0,$\left.01 ; \quad \eta^{2}=0.00 ; p>0.20\right)$ or performance $\left(F_{(1,231)}=0,93 ; \eta^{2}=0.00 ; p>0.20\right)$.

\section{Discussion}

This study aimed at analysing the effects of four different lighting colours on the thermal experience in an aircraft-like environment.

First of all, a thermal effect of the colours used was confirmed: Both yellow hues were perceived as being warmer than both blue lights. Thus, the selected colours fit well into the warm-cool categorisation according to Itten and proved to be useful as treatment factors. ${ }^{8}$ Confirming our first hypothesis, the thermal effect had an influence beyond colour sensation. The perception of the room temperature differed depending on the colour of lighting as well. In both yellow hues, room temperature was perceived as being warmer than in blue light, where the mean temperature ratings had a tendency towards being perceived as 'rather cold'. These findings confirm those derived from an earlier study in the light laboratory and reinforce the impact of the identified thermal effects of coloured light. ${ }^{27}$

Linking our results to former studies, they provide new evidence for the hue-heat hypothesis. ${ }^{24}$ The effects found by Fanger, Breum and Jerking $^{26}$ were confirmed and expanded for yellow and blue light in the application context of aircraft cabins. It was revealed that not only temperature sensation is affected by the lighting colour but also air quality is perceived as being higher and thus fresher in blue light. The perception of the climate parameters 'air draught' and 'humidity' was similar in all lighting conditions - no positive or negative effects concerning thermal comfort were observed (Table 4). All four hues induced a comfortable climate situation, which justifies the use of coloured light in an aircraft cabin to improve comfort for the passengers.

Concerning our second hypothesis we found effects of the lighting colour on the psychological and physiological well-being. When sitting in blue light, participants felt more alert than in yellow light. This effect can be clearly attributed to the colour of the light and is not due to its brightness. It further corresponds to results for stimulating melatonin suppression effects in blue light. ${ }^{19,20}$ Still, the participants' level of alertness was not critically high - an important fact regarding the practical usage of blue light in aircraft cabins. Passengers have to be able to relax during a flight and should not be stressed artificially. During our study, relaxation was predominant: Participants felt calm and balanced. The participants' mood was good in all kinds of hue; no bad atmosphere was created by the coloured lights.

Physiologically, subjects described themselves as being more efficient in both blue lights. Earlier work on the effects of colour temperatures on performance did not identify any or only differential effects for white light with high colour temperatures. ${ }^{31,32}$ But even though subjects felt concentrated and responsive sitting in blue light, their real performance level could not be analysed in the current study. With relation to their body, subjects felt mostly pleasant in all four hues. This physiological well-being can be understood as an additional facet of thermal comfort which supports the broad comfort impression the colours induce. 
Taken as a whole, our results are very promising: For all four colours tested meaningful influences on the perception of the thermal environment were found, while a comfortable environment could be established. With regard to the intention of manipulating the temperature impression in aircraft cabins, a first empirical basis is provided. Yellow and blue hues seem to be useful for increasing and decreasing temperature sensation respectively, which could further result in a reduction of ECS performance and energy consumption.

Regarding the practical implications of these results, passengers as well as cabin crew or even pilots could profit from the targeted usage of coloured light. During different flight phases, different lighting colours can be applied: For example during boarding, blue light can 'psychologically' cool down the cabin and improve the passengers' thermal comfort. For cabin crew or pilots, operational tasks can be accompanied by the appropriate lighting conditions. If personalised lighting zones are realised in future aircraft cabin design, coloured light could be used to account for individual needs such as gender differences regarding temperature sensations. ${ }^{28}$

On the basis of these findings, additional research questions can be addressed. Of special interest is if the effects remain the same when climate parameters are varied or how far a reduction of energy consumption can be demonstrated for aircraft cabins.

\section{Funding}

The study was supported by the Bundesministerium für Bildung und Forschung [grant number 03CL08].

\section{Acknowledgement}

We thank Don Harris from Coventry University for his valuable comments and advice.

\section{References}

1 Dumur E, Banard Y, Boy G. Designing for comfort. In: de Waars D, Brookuis KA, Weikert CM. (eds) Human Factors in Design. Maastricht: Shaker, 2004: 111-127.

2 CEN - European Committee for Standardization. DIN EN 4618. Aerospace Series - Aircraft Internal Air Quality Standards, Criteria and Determination Methods. Brussels: Beuth, 2009.

3 ASHRAE. Standard 161 - Air Quality within Commercial Aircraft. Atlanta: ASHRAE Inc., 2007.

4 Quehl J. Comfort Studies on Aircraft Interior Sound and Vibrations. Aachen: Shaker, 2001.

5 Baumann I, Trimmel M. Distribution of subjective assessments in a controlled aircraft environment. Aerospace Science and Technology 2011. DOI: 10.1016/ j.ast.2011.12.012.

6 Candas V, Dufour A. Thermal comfort: Multisensory interactions? Journal of Physiological Anthropology and Applied Human Science 2005; 24: 33-36.

7 Heijs W, Stringer P. Research on residential thermal comfort: Some contributions from environmental psychology. Journal of Environmental Psychology 1988; 8: 235-247.

8 Itten J. The Art of Color: The Subjective Experience and Objective Rationale of Color. New York: John Wiley, 2002.

9 Wright B, Rainwater L. The meanings of color. The Journal of General Psychology 1962; 67: 89-99.

10 Iskra-Golec IM, Wazna A, Smith L. Effects of blue-enriched light on the daily course of mood, sleepiness and light perception: A field experiment. Lighting Research and Technology 2012; 44: 506-513.

11 Boyce PR. Human Factors in Lighting. New York: Taylor and Francis, 2003.

12 National Lighting Bureau. Lighting and Human Performance - A Summary Report. Rosslyn, VA: NLB, 1989.

13 Van Hagen M, Galetzka M, Pruyn A, Peters J. Effects of colour and light on customer experience and time perception at a virtual railway station. In de Kort YAW, IJsselsteijn WA, Vogels IMLC, Aarts MPJ, Tenner AD, 
Smolders KCHJ. (eds) Proceedings Experiencing Light 2009 - International Conference on the Effects of Light on Wellbeing. Eindhoven: Eindhoven University of Technology, 2009: 137-145.

14 Veitch JA. Psychological processes influencing lighting quality. Journal of Illuminating Engineering Society 2001; 30: 124-140.

15 Küller R, Ballal S, Laike T, Mikellides B, Tonello G. The impact of light and color on psychological mood: A cross-cultural study of indoor work environment. Ergonomics 2006; 49: 1496-1507.

16 Valdez P, Mehrabian A. Effects of colour on emotion. Journal of Experimental Psychology 1994; 123: 394-409.

17 Gage J. Colour and Meaning. London: Thames and Hudson, 1999.

18 Greene TC, Bell PA. Additional considerations concerning the effects of "warm" and "cool" wall colours on energy conservation. Ergonomics 1980; 23: 949-954.

19 Budinger T, Vogel C. U.S. Patent No. 0219013. Westfield, NJ: U.S. Patent and Trademark Office, 2008.

20 Thapan K, Arendt J, Skene DJ. An action spectrum for melatonin suppression: Evidence for a novel non-rod, non-cone photoreceptor system in humans. Journal of Physiology 2001; 535: 261-267.

21 Cajochen C, Münch M, Kobialka S, Kräuchi K, Steiner R, Oelhafen P, Orgül S, WirzJustice A. High sensitivity of human melatonin, alertness, thermoregulation, and heart rate to short wavelength light. The Journal of Clinical Endocrinology and Metabolism 2005; 90: 1311-1316.

22 Lockley SW, Evans EE, Scheer FA, Brainard GC, Czeisler CA, Aeschbach D. Short-wavelength sensitivity for the direct effects of light on alertness, vigilance, and the waking electroencephalogram in humans. Sleep 2006; 29: 161-168.

23 Vandewalle G, Maquet P, Dijk D-J. Light as a modulator of cognitive brain function. Trends in Cognitive Sciences 2009; 13: 429-438.
24 Bennet CA, Rey P. What's so hot about red? Human Factors 1972; 14: 149-154.

25 Berry PC. Effect of colored illumination upon perceived temperature. Journal of Applied Psychology 1961; 45: 248-250.

26 Fanger P, Breum N, Jerking E. Can colour and noise influence man's thermal comfort? Ergonomics 1977; 20: 11-18.

27 Marggraf-Micheel C, Winzen J, Albers F. Klimaempfinden und Komfort in der Flugzeugkabine moderiert durch farbiges Licht?! - Ergebnisse einer Studie aus dem Projekt LiKab: Proceedings of Deutscher Luftund Raumfahrtkongress. Bonn, Germany: DGLR e.V., 2011: 1119-1128.

28 Marggraf-Micheel C, Rütten M, Piewald C. Thermal comfort in the aircraft cabin: The potential of objective and subjective measurement: Proceedings of CEAS-European Air and Space Conference. Manchester, UK, 2009: No. 187.

29 Steyer R, Schwenkmezger P, Notz P, Eid M. Der Mehrdimensionale Befindlichkeitsfragebogen (MDBF). Handanweisung [ A Multidimensional Questionnaire for Subjective Well-being (MDBF). Manual]. Göttingen, Germany: Hogrefe, 1997.

30 Frank R. FAW-Fragebogen zur Erfassung des aktuellen körperlichen Wohlbefindens. In Schumacher J, Klaiberg A, Brähler E. (eds) Diagnostische Verfahren zu Lebensqualität und Wohlbefinden [FAW-Questionnaire to assess current physiological well-being. In Schumacher J, Klaiberg A, Brähler E. (eds) Diagnostic Instruments for the Assessment of Life Quality and Well-being]. Göttingen, Germany: Hogrefe, 2003: 116-121.

31 Boray PF, Gifford R, Rosenblood L. Effects of warm white, cool white and full-spectrum fluorescent lighting on simple cognitive performance, mood and ratings of others. Journal of Environmental Psychology 1989; 9: 297-308.

32 Knez I. Effects of indoor lighting on mood and cognition. Journal of Environmental Psychology 1995; 15: 39-51. 